\title{
A study of analysis of LA remodelling and pathophysiologic determinants of LA volume in patients with LV dysfunction in patients with dilated cardiomyopathy
}

\author{
Reddi Basha Saheb Shaik ${ }^{1}$, Sambasiva Reddy N ${ }^{2 *}$
}

\author{
${ }^{1}$ Assistant Professor Department of Cardiology, Narayana Medical College \& Hospital, Chintareddy Palem, Nellore, Andhra Pradesh, INDIA. \\ ${ }^{2}$ Consultant Cardiologist, PESIMSR, Kuppam, Andhra Pradesh, INDIA. \\ Email: sivareddymbbs@gmail.com
}

\section{$\underline{\text { Abstract }}$}

\begin{abstract}
Background: Dilated cardiomyopathy represents the final common pathway produced by a variety of ischemic, toxic, metabolic and immunological mechanisms damaging the heart muscle. Recently, it has been shown that LA volume provides a more accurate measure of LA size than conventional M-mode LA dimension. Transthoracic echocardiography is most commonly used in daily clinical practice to assess LA size. Aim and objective: To analyze the degree of LA remodeling and the pathophysiologic determinants of LA volume in patients with LV systolic dysfunction in patients with dilated cardiomyopathy Methodology: Present prospective study was carried out on patients with a diagnosis of DCMP. Sex matched controls were recruited. The left atrial functions of the patients were evaluated by performing transthoracic echocardiography. The LV ejection fraction, LV volumes, and LV mass were determined. Mitral E-wave (E) and A-wave (A) velocities, E/A ratio, and E-wave deceleration time (DTE) is also measured off-line. Mitral regurgitation was assessed by color flow Doppler echocardiography. Data was analyzed with appropriate statistical tests. Results: Mean age of the study population was $36.08 \pm 16.13$ years. Patients with DCM showed a larger LA volume $(75.57 \pm 27.60 \mathrm{ml}$, $)$ compared with normal control subjects $(58.57 \pm 21.37 \mathrm{p}<0.016)$. Differences in the E-wave velocity $(0.92 \pm 0.25 \mathrm{vs} .1 .07 \pm 0.20 ; \mathrm{p}$ $<0.029)$, A-wave velocity $(0.68 \pm 0.32$ vs. $0.82 \pm 0.16 \mathrm{p}<0.066), \mathrm{E} / \mathrm{A}$ ratio $(1.71 \pm 0.90$ vs. $1.30 \pm 0.25 \mathrm{p}<0.05)$, or DT $(165 \pm 40.11$ vs. $197.25 \pm 24.33$ p < 0.002$)$ were observed between patients and control subjects. Em and LVEF were significant determinants of LA volume with $\mathrm{p}$ value of 0.03 and 0.01 .

Key Word: dilated cardiomyopathy.
\end{abstract}

*Address for Correspondence:

Dr Sambasiva Reddy N, Consultant Cardiologist, PESIMSR, Kuppam, Andhra Pradesh, INDIA.

Email: sivareddymbbs@gmail.com

Received Date: 11/11/2019 Revised Date: 04/12/2019 Accepted Date: 30/01/2020

DOI: https://doi.org/10.26611/10211523

This work is licensed under a Creative Commons Attribution-NonCommercial 4.0 International License. (oc)) EY-NC

\begin{tabular}{|l|l|}
\hline \multicolumn{2}{|c|}{ Access this article online } \\
\hline Quick Response Code: & Website: \\
\hline & www.medpulse.in \\
& \\
\hline
\end{tabular}

\section{INTRODUCTION}

Cardiomyopathy is a primary disorder of the heart muscle that causes abnormal myocardial performance and is not the result of disease or dysfunction of other cardiac structures. They are distinctive because they are not the result of pericardial, valvular, hypertensive or congenital diseases. ${ }^{1}$ Dilated cardiomyopathy accounts for upto $25 \%$ of all cases of CHF. The incidence of DCM is reported to be 5 to 8 cases per $1,00,000$ population per year. It occurs 3 times more frequently in males as compared to females. It is also more common in blacks. ${ }^{2}$ Dilated cardiomyopathy is the most common variety of cardiomyopathy. The most common dilated cardiomyopathy is the ischemic dilated cardiomyopathy followed by idiopathic / familial, diabetic 
and alcohol cardiomyopathy. ${ }^{3}$ Cardiomyopathy has many causes. Finding a specific cause for a cardiomyopathy is often difficult, especially when it is multifactorial. Traditionally, ischemic cardiomyopathy is listed as the most common cause of cardiomyopathy. Idiopathic cardiomyopathy is the second most common cause. Echocardiography has become one of the most useful and most efficient diagnostic modalities in attaining a diagnosis and classification of cardiomyopathy. ${ }^{4,5} \mathrm{Left}$ atrial (LA) enlargement has been proposed as a barometer of diastolic burden and a predictor of common cardiovascular outcomes such as atrial fibrillation, stroke, congestive heart failure, and cardiovascular death. Left atrium dilatation can occur in a broad spectrum of cardiovascular diseases including hypertension, left ventricular dysfunction, mitral valve disease and $A F$. In general, two major conditions are associated with LA dilatation: pressure overload and volume overload. ${ }^{6} \mathrm{LA}$ volume overload frequently occurs in the setting of mitral regurgitation. Pressure overload is most frequently caused by an increased LA afterload, secondary to mitral valve disease or left ventricular dysfunction. Pritchett et al. ${ }^{7}$ demonstrated a close correlation between LA volume and the severity of diastolic dysfunction after adjusting for the presence of covariates including age, gender, cardiovascular disease, ejection fraction and left ventricular mass. Accordingly, it has been suggested that whereas LA volumes represent long-term exposure to elevated pressures, Doppler measures of filling pressures rather represent the actual left ventricular filling pressures at one point in time. ${ }^{8}$ Different non-invasive imaging modalities are available for assessment of LA size and anatomy. Transthoracic echocardiography is most commonly used in daily clinical practice to assess LA size. Present study was conducted to analyze the degree of LA remodeling and the pathophysiologic determinants of LA volume in patients with LV systolic dysfunction in patients with dilated cardiomyopathy.

Aim and objective: To analyze the degree of LA remodeling and the pathophysiologic determinants of LA volume in patients with LV systolic dysfunction in patients with dilated cardiomyopathy

\section{MATERIAL AND METHODS}

Present study was prospective study. It was carried out on patients admitted in ICU at Narayana Medical College and Hospital, Chintareddy. Study period January 2019 to September 2019. A total of 50 patients (30 men and 20 women) were recruited as cases. Patients with a diagnosis of DCMP who had a complete echocardiographic Doppler examination within one month of clinical evaluation and who were followed for 3 months formed the study population. Sex matched controls were recruited. Twenty subjects in sinus rhythm, with no history of cardiac disease and with entirely normal echocardiographic findings were control group participants.

Inclusion Criteria: 1. Patients with Congestive Heart failure (New York Heart Association class II to IV) for $\geq 3$ months while receiving medical treatment 2 . Consecutive patients who had a complete echocardiographic Doppler examination with a LV ejection fraction of $\leq 40 \%$ on the basis of echocardiographic evaluation using a modified Simpson's method. 3. Patients above age of 14 years

Exclusion Criteria: 1. Patients with Significant organic mitral or aortic valve disease 2. Patients with amyloidosis or constrictive pericarditis 3. Patients with A recent myocardial infarction $<6$ months.

Study was approved by ethical committee of the institute. A valid written consent was taken from patients or guardians of the patients after explaining study to them. Data was collected with pretested questionnaire. Data included demographic data and detailed clinical history. A through clinical examination was done. All patients underwent transthoracic echocardiography. The left atrial functions of the patients were evaluated by performing transthoracic echocardiography. Echocardiographic images were acquired in the standard parasternal and apical views. The LV ejection fraction, LV volumes, and LV mass were determined for a total number of three times; first at the time of the visit to the hospital, and then at end of first and sixth months of follow up. Left atrial maximal volume (LAmax) is measured at LV end systole, and LA minimal volume (LAmin) at LV end diastole from the apical four-chamber view (area-length method). Left ventricular end-diastolic and end-systolic volumes (arealength method) and EF is measured off-line from the apical four-chamber view. Mitral E-wave (E) and A-wave (A) velocities, E/A ratio, and E-wave deceleration time (DTE) is also measured off-line. The last variable is measured as the interval (in milliseconds) from peak early mitral filling to an extrapolation of the deceleration to $0 \mathrm{~m} / \mathrm{s}$. All measurements were obtained from the mean of 3 beats for patients in sinus rhythm and 5 beats for those with AF. A restrictive mitral inflow pattern was defined as an $\mathrm{E} / \mathrm{A}>2$ or between 1 and 2 and DTE $<140 \mathrm{~ms}$ in patients in sinus rhythm or a DTE $<140 \mathrm{~ms}$ in patients with AF. Mitral regurgitation was assessed by color flow Doppler echocardiography. Data was analyzed by using SPSS software version 20.

\section{RESULTS}

In our study, Mean age of the study population was 36.08 \pm 16.13 years. Mean duration of symptoms was 1.8 years. The etiology of cardiomyopathy was idiopathic in $76 \%$, viral myocarditis in $12 \%$, peripartum cardiomyopathy in $8 \%$ and drug induced in $4 \%$. (fig 1) Table 1 shows 
comparison of various parameters in patient group and control group. Mean age in the patient group was $36.05 \pm 8.13$ and mean age in control group was $40.50 \pm 8.40$ years. This difference between the two group was statistically significant $(\mathrm{p}<0.001)$. Mean body surface area in both the group was comparable (p.0.05). Left Atrial Volume (LAV) at admission was $75.57 \pm 27.60 \mathrm{ml}$ in patients group and $58.57 \pm 21.37 \mathrm{ml}$ in control group. Difference in LAV at admission in both the group was statistically significant $(\mathrm{p}<0.01)$. Left atrial volume index at admission in patients group was $(45.26 \pm 16.13 \mathrm{ml} / \mathrm{m} 2)$ significantly higher than control group $(34.70 \pm 12.95$ $\mathrm{ml} / \mathrm{m} 2)$. $(\mathrm{p}<0.01)$ Left ventricular ejection fraction in patient's group (33.32 \pm 6.65$)$ was significantly lower than control group $(62.95 \pm 6.77) .(p<0.0001)$. Left ventricle internal dimensions at end diastole in patients group was $5.89 \pm 0.59$ and in control group was $4.6 \pm 0.51$. The difference between both the group was statistically significant $(p<0.001)$. Left ventricular lateral wall early diastolic mitral annulus velocity $(\mathrm{Em})$ in patient;s group $(0.92 \pm 0.25)$ was significantly lower than control group $(1.07 \pm 0.20) .(p=<0.029)$. E/A ratio in patients group was
$1.71 \pm 0.90$ and in control group was $1.30 \pm 0.25$. It shows more restrictive mitral inflow pattern in patient's group $(p<0.05)$. E-wave deceleration time (DTE) in patient's group was $165.74 \pm 40.11 \mathrm{~ms}$ and in control group it was $197 \pm 24.23 \mathrm{~ms}$. Difference between these group was statistically significant. $(p<0.05)$. Left ventricular mass in both the group was comparable. Table 2 shows Comparison of Echo parameters at admission and at 6 months in patient's group. Left Atrial Volume at admission was $75.57 \pm 27.60 \mathrm{ml}$. It decreased to $66.33 \pm 24.69 \mathrm{ml}$. This difference was statistically not significant $(\mathrm{p}=0.08)$. Left atrial volume Index at admission was $45.26 \pm 16.13 \mathrm{ml} / \mathrm{m} 2$. It significantly reduced to $38.40 \pm 14.82(\mathrm{p}=0.02)$. The determinants of LA volume were defined by means of linear regression analysis (table 3). Em and LVEF were significant determinants of LA volume with $p$ value of 0.03 and 0.01. DTE and E/A ratio were not significant in our study. There was negative correlation between the LA volume and LA volume index. In this study, the predictive role of LA volume proved to be more powerful than MR, independent of the degree of MR.(table 4)

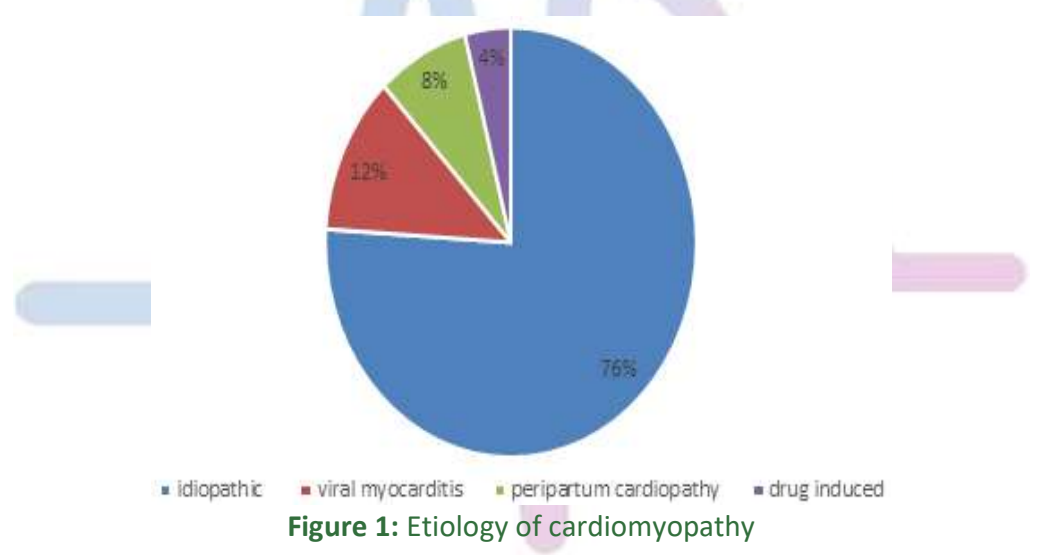

Table 1: Comparison of patient's group and control group according to baseline parameters

\begin{tabular}{ccccc}
\hline S.no & Parameters & Pt. Group & Control & $\begin{array}{c}\text { Significance } \\
(\mathrm{p})\end{array}$ \\
\hline 1 & & & & $<0.0001$ \\
2 & Age & $36.05 \pm 8.13$ & $40.50 \pm 8.40$ & NS \\
3 & BSA & $1.67 \pm 0.10$ & $1.69 \pm 0.15$ & $<0.016$ \\
4 & Cal. LAV (At Adm) & $75.57 \pm 27.60$ & $58.57 \pm 21.37$ & $<0.01$ \\
5 & LAV I (At Adm) & $45.26 \pm 16.13$ & $34.70 \pm 12.95$ & $<0.0001$ \\
6 & LV EF & $33.32 \pm 6.65$ & $62.95 \pm 6.77$ & $<0.0001$ \\
7 & LV EDD & $5.89 \pm 0.59$ & $4.6 \pm 0.51$ & $<0.029$ \\
8 & Em & $0.92 \pm 0.25$ & $1.07 \pm 0.20$ & $<0.05$ \\
9 & E/A Ratio & $1.71 \pm 0.90$ & $1.30 \pm 0.25$ & $<0.002$ \\
10 & DTE & $165.74 \pm 40.11$ & $197 \pm 24.23$ & NS \\
\hline
\end{tabular}

Table 2: Comparison of Echo parameters at admission and at 6 months in patient's group

\begin{tabular}{cccc}
\hline Echo parameters & At admission & At 6 months & Significance $(\mathrm{p})$ \\
\hline Cal. LAV $(\mathrm{ml})$ & $75.57 \pm 27.60$ & $66.33 \pm 24.69$ & $\mathrm{P}=0.08$ \\
LAVI $(\mathrm{ml} / \mathrm{m} 2)$ & $45.26 \pm 16.13$ & $38.40 \pm 14.82$ & $\mathrm{P}=0.02$ \\
\hline
\end{tabular}


Table 3: Determinants of LA volume

\begin{tabular}{cccc}
\hline S. No & Parameters & R & Significance \\
\hline 1 & Em & 0.333 & $<0.03$ \\
2 & LV EF & -0.347 & $<0.012$ \\
3 & DTE & 0.259 & $<0.095$ \\
4 & E/A Ratio & 0.014 & NS \\
\hline
\end{tabular}

\begin{tabular}{cccc}
\multicolumn{4}{c}{ Table 4: Correlation of LAV Between Duration and Degree ff MR Severity } \\
\hline S. No & Parameters & Duration & MR Severity \\
\hline 1 & Cal LA V at Adm. & r $0.339(p<0.016)$ & $0.115(p=N S)$ \\
2 & Cal. LA V at 6 months & $r 0.316(p<0.02)$ & $0.106(p=N S)$ \\
3 & LA V I at Adm. & $r 0.346(p<0.013)$ & $0.093(p=N S)$ \\
\hline
\end{tabular}

\section{DISCUSSION}

In our study, Mean age of the study population was 36.08 \pm 16.13 years. Mean duration of symptoms was 1.8 years. In the study by Pinamonti et al.., the overall population had a relatively young mean age ( $39 \pm 15$ years). This casts doubt on the accuracy of mitral parameters in describing restrictive physiology, because of the strong age dependence of the mitral pattern. In our study, the etiology of cardiomyopathy was idiopathic in $76 \%$, viral myocarditis in $12 \%$, peripartum cardiomyopathy in $8 \%$ and drug induced in $4 \%$. Similar findings were seen in Parale et al. ${ }^{9}$ where idiopathic cardiomyopathy was observed in $75 \%$ and peripartum cardiomyopathy was seen in $12 \%$ patients. other etiology in the study were diabetic and alcoholic cardiomyopathy. In our study, Mean body surface area in both the group was comparable (p.0.05). Body size is a major determinant of LA size. To adjust for this influence, LA size should be indexed to a measure of body size, most commonly to body surface area. Indeed, age-related LA enlargement is a reflection of the pathophysiologic perturbations that often accompany advancing age rather than a consequence of chronologic aging.

It has been shown that advancing age alone does not independently contribute to LA enlargement, and the impact of gender on LA volume can largely be accounted for by the differences in body surface area between men and women. Therefore, enlargement of the left atrium reflects remodeling associated with pathophysiologic processes. In our study, Patients with DCM showed a larger LA volume $(75.57 \pm 27.60 \mathrm{ml}$, $)$ compared with normal control subjects $(58.57 \pm 21.37 \mathrm{p}<0.016)$. Differences in the E-wave velocity $(0.92 \pm 0.25$ vs. $1.07 \pm$ $0.20 ; \mathrm{p}<0.029)$, A-wave velocity $(0.68 \pm 0.32$ vs. $0.82 \pm$ $0.16 \mathrm{p}<0.066)$, E/A ratio $(1.71 \pm 0.90$ vs. $1.30 \pm 0.25 \mathrm{p}<$ $0.05)$, or DT $(165 \pm 40.11$ vs. $197.25 \pm 24.33 p<0.002)$ were observed between patients and control subjects. In our study we found a relation between atrial volume and diastolic markers but it was statistically not significant. Previous studies have shown that LA size is a good diastolic marker. ${ }^{10,11}$ In this study, the predictive role of
LA volume proved to be more powerful than MR, independent of the degree of MR, and it was confirmed in both the group of patients with and the group without MR. Mitral regurgitant volume is a key determinant of atrial volume, ${ }^{12}$ which may reflect the severity, duration, and prognosis of MR ${ }^{13}$ in this study, LA volume correlated weakly but significantly with the duration of the disease. Evidence for a prognostic role for LA volume to predict incident $\mathrm{CHF}$ is emerging. In a large prospective, population-based study, subjects with incident CHF during follow-up had slightly higher baseline LA linear diameters (39 mm vs. $37 \mathrm{~mm}$ for women [p $<0.01$ ], $41 \mathrm{~mm}$ vs. 39 $\mathrm{mm}$ for men $[\mathrm{p}<0.01])$. In a study of older adults referred for echocardiography, LA volume $32 \mathrm{ml} / \mathrm{m} 2$ was associated with increased incidence of CHF, independent of age, myocardial infarction, diabetes mellitus, hypertension, LV hypertrophy, and mitral inflow velocities (HR 1.97, 95\% CI 1.4 to 2.7). Furthermore, in subjects with an LV ejection fraction $50 \%$ at baseline and within four weeks of incident $\mathrm{CHF}$, there was an increase of 8 $\mathrm{ml} / \mathrm{m} 2$ in LA volume from baseline to CHF diagnosis, reflecting the added burden of diastolic dysfunction during the period of transition from preclinical to clinical status. In patients with chronic heart failure due to DCM, diastolic dysfunction is an important hallmark of the severity of the disease. The degree of diastolic impairment correlates with symptoms and prognosis more closely than Ejection Fraction. ${ }^{14-16}$

\section{CONCLUSION}

LA remodeling is frequent, in patients with DCM. Left atrial volume is mainly determined by the degree of LV dilation, diastolic dysfunction, and the extent of MR.

\section{REFERENCES}

1. Zipes D, Libby P, Bonow R, Braunwald E. A Braunwald's heart disease - Textbook of Cardiovascular Medicine: The cardiomyopathies. 7th Ed. Philadelphia: Elsivier Saunders;2005.

2. Anderson KM, Kannel WB. Prevalence of congestive heart failure in Framingham Heart study subjects. Circulation 1994;13:S107-S112. 
3. Richerdson. WHO Report on classification of cardiomyopathy. Br. Heart J. 1980;44:680-682.

4. Tsang TS, Barnes ME, Gersh BJ, et al.. Prediction of risk for first age-related cardiovascular events in an elderly population: the incremental value of echocardiography. J Am Coll Cardiol2003;42:1199-205.

5. Osranek M, Bursi F, Bailey KR, et al.. Left atrial volume predicts cardiovascular events in patients originally diagnosed with lone atrial fibrillation: three-decade follow-up. Eur Heart J2005;26:2556-61.

6. Lang RM, Bierig $\mathrm{M}$, Devereux RB, et al.. Recommendations for chamber quantificationa report from the American Society of Echocardiography's Guidelines and Standards Committee and the Chamber Quantification Writing Group, developed in conjunction with the European Association of Echocardiography, a branch of the European Society of Cardiology. J Am Soc Echocardiogr 2005;18:1440-1463.

7. Thomas L, Levett K, Boyd A, Leung DY, Schiller NB, Ross DL. Compensatory changes in atrial volumes with normal agingis atrial enlargement inevitable? J Am Coll Cardiol 2002;40:1630-1635.

8. Prioli A, Marino P, Lanzoni L, Zardini P. Increasing degrees of left ventricular filling impairment modulate left atrial function in humans Am J Cardiol 1998;82:756-761.

9. Parale GP, Yadav NA, Kulkarni PM et al., clinical profile cardiomyopathy in suburban part of Maharashtra, JAPI 2001;49:182-183.
10. Pritchett AM, Jacobsen SJ, Mahoney DW, Rodeheffer RJ, Bailey KR, Redfield MM. Left atrial volume as an index of left atrial sizea population-based study. J Am Coll Cardiol 2003;41:1036-1043.

11. Tsang TS, Barnes ME, Gersh BJ, Bailey KR, Seward JB. Left atrial volume as a morphophysiologic expression of left ventricular diastolic dysfunction and relation to cardiovascular risk burden Am J Cardiol 2002;90:12841289.

12. Appleton CP. Hemodynamic determinants of Doppler pulmonary venous flow velocity componentsnew insights from studies in lightly sedated normal dogs. J Am Coll Cardiol 1997;30:1562-1574.

13. Kennedy JW, Yarnall SR, Murray JA, Figley MM. Quantitative angiocardiography. IV. Relationships of left atrial and ventricular pressure and volume in mitral valve disease Circulation 1970;41:817-824.

14. Stefanadis C, Dernellis J, Toutouzas P. A clinical appraisal of left atrial function. Eur Heart J2001;22:22-36.

15. Reant $\mathrm{P}$, Lafitte $\mathrm{S}$, Jais $\mathrm{P}$, et al.. Reverse remodeling of the left cardiac chambers after catheter ablation after 1 year in a series of patients with isolated atrial fibrillation. Circulation2005;112:2896-903.

16. Lester SJ, Ryan EW, Schiller NB, Foster E. Best method in clinical practice and in research studies to determine left atrial size Am J Cardiol 1999;84:829-832.

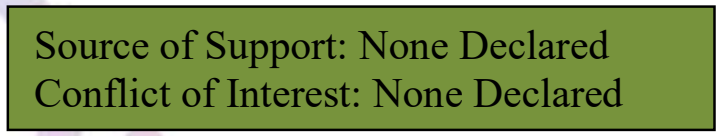

Policy for Articles with Open Access:

Authors who publish with MedPulse International Journal of Medicine, Print ISSN: 2550-7583, Online ISSN: 2636-4751 agree to the following terms: Authors retain copyright and grant the journal right of first publication with the work simultaneously licensed under a Creative Commons Attribution License that allows others to share the work with an acknowledgement of the work's authorship and initial publication in this journal.

Authors are permitted and encouraged to post links to their work online (e.g., in institutional repositories or on their website) prior to and during the submission process, as it can lead to productive exchanges, as well as earlier and greater citation of published work. 